\title{
Necrofilia visual: análisis de contenido y receptores de La Opinión de la Tarde
}

Laura Orellana Trinidad*

Universidad Iberoamericana-Laguna

Es INDISCUTIBLE, que el fenómeno de la violencia y su supuesta relación con los medios de comunicación, ha sido una preocupación constante en los teóricos de la comunicación. Para De Fleur y Ball-Rokeach este interés tuvo un mayor auge en la década de los sesenta con la expansión de la televisión, ya que algunos investigadores intentaron la búsqueda de una asociación entre la violencia real y los contenidos violentos que presentaba este medio electrónico. Muchos de estos estudios partían de la pregunta ¿Qué efectos tienen en los receptores, los contenidos violentos o agresivos que se presentan en los medios de comunicación?, llegando a conclusiones sumamente disímbolas. Por ejemplo, la Teoría de la catarsis sostenía que las frustraciones y agresiones de los sujetos se catalizaban mediante la exposición a la violencia de los medios, disminuyendo la posibilidad de verdaderos actos agresivos y la Teoría de los efectos del estímulo, por el contrario, suponía que "...la exposición a los estímulos agresivos habrá de incrementar la susceptibilidad de una persona para la excitación fisiológica y emocional, lo que a su vez habrá de aumentar la probabilidad de una conducta agresiva" (De Fleur y Ball-Rokeach 1987). A pesar de múltiples investigaciones, es posible decir que no se avanzó mucho desde este perspectiva. Muchas de ellas utilizaron el experimento como via metodológica, pero han sido muy cuestionadas debido a que se centraron sólo en los efectos a corto plazo.

- En esta investigación colaboraron los siguientes alumnos de la carrera de Comunicación de la UiA-Laguna en el periodo otoño de 1995: Yadira Berumen, Eunice Betancourt, Miguel Delgado, Araceli Gamboa, Cinthya Gaspar, Melina Flores, Gabriela Hernández, Miriam Hernández, Carlos Hernández, Jorge Maldonado, Miguel Angel Martinez, Yolanda Meraz, Rodrigo Medina, Mayela Muro, Lourdes Murillo, Sergio Ochoa, Mónica Orduño, Juan Ma. Reza, Ana Portilla. 
Necrofilia visual: Análisis de contenido y receptores ...

En los setentas, desde la corriente del imperialismo cultural se efectuaron algunos estudios de contenido de la violencia en los mass media. Herner, en un estudio muy amplio sobre procesos de producción y contenido de las historietas y fotonovelas en México, describe cómo la fórmula sexo-violencia era un ingrediente muy importante en estas publicaciones (Herner 1979). No obstante, estos trabajos no tomaban en cuenta a los receptores pues "...bastaba identificar los condicionantes económicos, políticos e ideológicos presentes en el momento de la producción para inferir que los mensajes reflejarían necesariamente la ideología de la clase dominante y que los receptores asimilarian incondicionalmente dichas visiones del mundo y de la vida" (Lozano 1996:119).

Hoy en día, la violencia, es una de las temáticas más importantes de las agendas de los medios. Esto tiene que ver definitivamente, con situaciones del ámbito de lo real. En México, las convulsiones sociales, económicas y políticas han sido factores, al parecer, de una inusitada violencia. Hace tres años se realizó un estudio en el cual se comparaba las muertes violentas entre 31 países del mundo, destacando nuestro país en primer lugar con 45 homicidios masculinos por cada 100,000 hombres. Esto representa el doble que los Estados Unidos y setenta veces más que las muertes de este tipo en Austria, Noruega - Japón (cfr. Goldsmith y Crinkel 1993). Si bien es difícil negar este aspecto que se presenta ante nuestros ojos, los medios lo han convertido en un mecanismo para conseguir audiencia. No sólo los programas de ficción incorporan la violencia, sino también los espacios noticiosos que le dan cada vez mayor importancia a la nota roja en detrimento de noticias políticas o económicas. Este tipo de información se refuerza significativamente con imágenes, tanto en la televisión como en la prensa, para provocar un mayor impacto en los receptores.

A pesar de ser un fenómeno que se multiplica con rapidez en los medios, ha sido poco abordado. Cervantes (1996) avanza sobre este campo en un estudio reciente en el que analiza los valores noticiosos en el periodismo televisivo de nota roja Sin embargo, ella misma indica que en México sólo se registran ocho trabajos cuya fuente es la información policiaca.

La presente investigación intenta abordar precisamente este género periodístico -la nota roja- en un diario vespertino de la ciudad de Torreón, Coahuila. La Opinión de la Tarde cambió su contenido y formato a partir de junio de 1993 con la compra del rotativo por la empresa Multimedios Estrellas de Oro, que además controla un canal de televisión y dos estaciones de radio en la misma localidad.

El vespertino se concibió desde 1955 , como un periódico que recogería las noticias que surgían durante la noche y no se alcanzaban a publicar en el diario de la mañana $L a$ 
Opinión. Se divulgaba información regional, nacional, internacional. además de algunas notas policiacas. También habia una sección de espectáculos y deportes. Al inicio contaba con ocho páginas.

Este diario sufrió cambios -básicamente de formato- durante 38 años, pero la transformación radical vino en 1993. El periódico desde este momento alcanzó las 24 páginas con fotografias a color cuyo atractivo principal es la nota roja que incluye el reporte de lo que se consideran transgresiones a la ley como homicidios, robo, asaltos, etcétera, así como accidentes y suicidios. Las noticias nacionales y regionales de temas como economía o política se sustituyeron por secciones como Dramas de la vida, Historias de fantasmas, Corazones solitarios, Cartas desde la cárcel de mujeres, Historias y vivencias de traileros, entre otras.

Llaman la atención varios aspectos: este periódico sale a la venta entre las 10 y 11 de la mañana, es decir, ya no tiene como función recoger las noticias que no pudieron publicarse en La Opinión porque sale unas cuantas horas después de éste; su tiraje alcanza, según datos no oficiales, los 45,000 ejemplares diarios que a decir del mismo informante, rebasa por 10,000 números al matutino. En una entrevista realizada el 7 de septiembre de 1995 al jefe de información de La Opinión de la Tarde, Felipe de Jesús González, confirmó que cuenta con un mayor número de lectores. Para la empresa, los dos diarios se dirigen a públicos distintos. Específicamente, La Opinión de la Tarde se orienta a un sector urbano o suburbano que según González "...tiene el nivel de un empleado, de alguien que llegó hasta preparatoria". Para el jefe de redactores y reporteros de dicho diario, Enrique Jaramillo, entrevistado en la misma fecha "...la nota roja interesa a los pobres, por ejemplo, la colonia 'Valle Dorado' cuando es testigo de algún acontecimiento trágico como un 'picado' o algún caso de infidelidad, toda la colonia compra el periódico y se entera; también las colonias anexas para saber quién fue, porque todos se conocen". Cabe añadir, por último, que el costo del vespertino es de $\$ 3.00$, el mismo precio que $L a$ Opinión.

El estudio de este periódico incorpora tanto el análisis de contenido del mismo, así como el de sus receptores.

Para analizar el discurso noticioso de la llamada nota roja y avanzar en el examen de este fenómeno, es imprescindible considerarlo como una construcción (Cfr. Bisbal 1995: 48) partiendo del enfoque de la Sociología de la producción de mensajes.

Los teóricos que desarrollan esta corriente, conciben que las empresas periodísticas siguen los criterios de cualquier organización cuyo objetivo es la manufacturación de un producto y estos lineamientos están relacionados con la lógica productiva dominante. 
Necrofilia visual: Análisis de contenido y receptores ...

Así, la elaboración de los productos de estas empresas (noticias), responde a diversos condicionantes. Los mensajes se encuentran impactados por las necesidades económicas de la empresa y sus políticas corporativas; por una estandarización de los procesos de recolección, selección, elaboración y transmisión de los mismos que permiten contar con el producto cuando se requiere; por las características individuales de quienes están involucrados en la organización periodística dando por resultado un producto simbólico, una imagen de la realidad, una representación de lo social, un imaginario colectivo que enfatiza unos aspectos soslayando otros. González Molina (1987) en su estudio sobre la producción de noticias en Televisa, los identifica como las dimensiones institucional, burocrática y profesional. Cervantes (1996) por su parte, toma a varios autores para construir un esquema similar con distintos niveles para analizar la información policiaca del noticiero jalisciense $A l$ Tanto, éstos son: el individual o profesional; las rutinas de producción/organizacional; el nivel institucional y añade el ideológico que de hecho, como ella misma señala, se separa por una convención metodológica pero se encuentra presente en los demás.

El nivel institucional explora los factores políticos y económicos que inciden en la producción de noticias así como la política de la organización al interior; la vinculación y presiones en relación a otros medios o instituciones. Aunque esta dimensión no es objeto de estudio en la presente investigación, sí se puede detectar la importancia que tiene la nota roja como estrategia para la corporación regiomontana Multimedios Estrellas de Oro: los vespertinos, tanto en Monterrey como en Torreón, han contribuido no sólo al logro de metas económicas que solidifican la empresa, sino a su expansión. En la entrevista mencionada anteriormente con el jefe de información de La Opinión de la Tarde, Felipe de Jesús González, este señaló que el incremento del tiraje de este periódico permitiría abrir otra rotativa y que a diferencia de otros países en donde ha habido un cierre masivo de empresas periodísticas por el crecimiento de los medios electrónicos, el vespertino constituía -en sus palabras-un caso atípico que no sigue esta tendencia. Otras estrategias visibles son: la segmentación de las audiencias (el vespertino no le "roba" lectores al matutino, sino que se incrementa la audiencia global), la centralización en la producción de noticias (la empresa periodística surte de noticias al Canal 9 y las estaciones de radio Estereo Recuerdo y-Super 92). Asimismo, un medio sirve para promocionar a otro, por ejemplo, el noticiero de mediodía del Canal 9 normalmente promociona La Opinión de la Tarde al finalizar su edición.

El nivel organizacional (burocrático) o de rutinas de producción, estudia el proceso mismo que se instaura en cada empresa periodística para producir cotidianamente las 
noticias: los horarios que se imponen, el número de notas que cada reportero debe conseguir, la forma en cómo se accede a los hechos, así como la manera en que los reporteros socializan aquéllo que es noticiable para la organización. Aquí encontramos implícito el nivel ideológico, ya que no es posible asegurar que existe la pretendida "objetividad" que los medios señalan como su misión. Lozano (1996:69) enfatiza que "...los reporteros no son objetivos en cuanto a que es su cultura y su ideología lo que los motiva a considerar ciertos hechos como normales y otros como anormales, como desviaciones de la regla".

En relación a la nota roja, los reporteros, mediante su prácticas profesionales, realizan una interpretación permeados de un imaginario social sobre la violencia que se plasma en este tipo de noticias. Este imaginario está fundado principalmente en la concepción de que los conflictos son hechos naturales, no sociales y están centrados en ciertos agentes violentos quienes constantemente transgreden las normas y leyes de la colectividad. Parecería así, que la violencia la ejercen individuos o grupos especificos que pueden controlarse mediante sanciones.

La individualización de la violencia en la nota roja forzosamente lleva a la ubicación de un otro transgresor. Este, se construye en la prensa "amarillista" con referentes simbólicos, sociales y culturales que se consideran violentos mediante una serie de mitos y creencias sociales que forman parte de la cosmovisión de la sociedad. El transgresor está identificado: usa cienta vestimenta, proviene de cierto tipo de colonias y de determinados grupos sociales. Sin embargo, Uribe (1995:58) expresa con justa razón que: "Lo que nos llama la atención frente a la violencia es que ella no se explica sólo por los actos perpetrados por los violentos, sin ir a los procesos donde estos verifican sus acciones. Procesos históricos, sociales, políticos, económicos y culturales que, por supuesto, se hayan dinamizados por diferentes actores en el marco de una integralidad de la cual no es posible aislamos ni a los unos ni a los otros, so pena de caer en una comprensión deformada y sesgada de ambas situaciones".

La dificultad estriba en que los periodistas admiten que pueden acceder a la realidad sin ninguna clase de mediaciones, que es factible ser objetivos -neutrales- sin su intervención, que los hechos están en la calle, listos para ser llevados al periódico. Cervantes (1996:93) contribuye a clarificar la forma en que las rutinas productivas de estos profesionales tienen a coincidir con las posiciones hegemónicas: "En el nivel interno de los procesos y criterios de selección de notas por parte de editores o jefes de información, los valores noticiosos han demostrado jugar un rol fundamental, pero tal vez su principal función se ubique en el plano amplio del orden y del control sociales...". 
Necrofilia visual: Análisis de contenido y receptores ...

En el nivel profesional o individual se encuentran los condicionantes propios de los profesionales dedicados al periodismo. Sus características personales como sexo, edad, clase social; sus valores y creencias contribuyen a que se considere un cierto tipo de información como relevante. Esta dimensión, que no fue estudiada en el presente trabajo, es la que tiene menos incidencia ya que los valores profesionales introyectados a partir de las prácticas profesionales tienden, en cierta medida, a estandarizar los procesos de recolección, selección y redacción. Si bien el análisis de contenido puede ayudar a clarificar la representación de la violencia que se tranmite a través de este medio, puede quedar inconcluso si no accedemos a los lectores asiduos de esta prensa popular. Además es posible pensar que así como "...las rutinas productivas y los criterios de importancia en su aplicación constante forman el marco institucional y profesional en el que es percibida la noticiabilidad de los acontecimientos, la constante enfatización de algunos temas, aspectos y problemas forma un marco interpretativo, un esquema de conocimientos, un frame, que se aplica (más o menos conscientemente) para dar sentido a lo que observamos" (Wolf 1991:165).

Exponer los dramas en la nota roja debía conducir, según Aubague (1987:151), a verdaderos actos de solidaridad humana al recordar a la colectividad el carácter sagrado de la vida. Sin embargo, en su análisis de la revista Alarma, muestra que en realidad se convierte en una distracción al instalarse el fenómeno rojo en el mundo cotidiano de los hombres y mujeres: "...la nota roja no es consumida según el rito ceremonial de la tragedia sino al comer, al viajar en metro, al tomar su café con leche".

En este estudio se coincide al señalar que Alarma atribuye la violencia al individuo. En Alarma la agresión no se presenta como histórica sino como natural y como tal debe castigarse. Esta revista, consumida preferentemente por receptores de las clases populares, muestra un mundo amenazado siempre por el caos, que se entiende como todo aquéllo que puede paralizar el buen funcionamiento de la sociedad. Para los sectores populares, esta transformación de la noticia en producto, les permite suponer que las imágenes del caos corresponden al caos en el que viven sin ninguna posibilidad de reflexión. Para los lectores pequeño-burgueses, Alarma les muestra la realidad de la que pudieron huir y no les corresponde. Les recuerda que gracias a sus méritos y a la adquisión de ese nuevo status, es prácticamente imposible que algún día pudieran ser actores participantes en la revista.

Sin embargo queda la duda: ¿Por qué tantos lectores? ¿Por qué si se muestran los horrores y el caos de la relación y la vivencia humana, el tiraje llega a sobrepasar al de los periódicos "serios" y "objetivos"? ¿Qué llama la atención este tipo de prensa?. 
Así pues es necesario considerar la otra parte: los receptores y su relación con el contenido de la nota roja. De nada sirve anatemizar a quien compra un periódico "amarillista" sin explorar los factores que inciden en su consumo.

Parece necesario ubicar las características y estética de este tipo de prensa para discutir su valor sociocultural y político (Gripsrud 1992). Algunos estudiosos señalan que una importante característica de la nota roja, ingrediente fundamental en la interpelación de los individuos, es el tratamiento y su escritura a modo de relato. Este aspecto constituye o marca una diferencia en cuanto al tono de "objetividad" que guardan las noticias económicas y políticas.

La nota roja es una pequeña historia centrada en un individuo, o si acaso en un pequeño grupo, en donde todos los detalles son necesarios para la explicación de lo que ocurrió. El melodrama, producto popular del siglo XIX, se basa en lo "elementalmente humano"; es decir aquéllos recursos que constituyen la vida misma como el amor, el odio, el pesar, la alegría, el enojo.

Parece que un acercamiento más literario permitiria entender la fascinación hacia la nota roja. El género de la tragedia no sitúa a los personajes en una posición de superioridad o inferioridad sino que justamente opera en el medio, en donde el personaje es un ser aislado y débil que coincide más con nuestro propio nivel de experiencia (Langer 1992).

Las historias que aparecen en los diarios "amarillistas", se ubican en la vida cotidiana y sus personajes, $\tan$ humanos, nos permiten identificarnos. De pronto sucede algo que trastoca esa cotidianidad: un homicidio, un accidente, un suicidio. Parecen sucesos que pueden pasarle a cualquiera. No hay una relación con las condiciones de vida sociales sino con la suerte. El drama es tal porque el individuo aparentemente pierde el control de su vivencia. Langer señala que "Muchas de las historias emergen de una concepción del mundo en la cual no se admite la posibilidad de control; donde la vida está sujeta a caprichosas fuerzas externas con las cuales choca indiscriminadamente, exponiendo a las personas a cambios radicales de fortuna y conflictos repentinos cada día" (Langer 1992: 123).

El tipo de periódico donde la nota roja es un atractivo fundamental, puede considerarse como popular porque incorpora una serie de mitos, creencias, supersticiones que operan en la explicación de los sucesos. Sin embargo, aunque estas notas contrastan abiertamente con las de los grupos dominante ("objetivas"), la prensa enfatiza aquéllos aspectos populares que indican que no se puede hacer nada frente a los acontecimientos. La atracción de la nota roja proviene de la identificación que puede sentirse frente a la experiencia humana, pero ésta no se localiza en términos de condiciones sociales, 
Necrofilia visual: Análisis de contenido y receptores ...

económicas, históricas, sino que retoma los aspectos fatalistas de las creencias y supersticiones.

La nota roja, al construirse como una historia en donde puede haber distintos relatores (testigos, víctimas, seres queridos afectados) ofrece múltiples puntos de identificación que contribuyen al interés de la misma.

Bajo estas concepciones se han planteado algunas interrogantes en cuanto al contenido y receptores de La Opinión de la Tarde: ¿qué elementos contribuyen a construir la nota roja de este diario?, ¿cuáles son los aspectos del relato presentes en ella?, ¿cuál es el imaginario social en relación a la violencia que prevalece en este vespertino?, ¿cómo se construye ese "otro" llamado delincuente?, ¿por qué las personas compran La Opinión de la Tarde?, ¿tienden a ubicar esta visión fatalista de los sucesos?, ¿conciben la violencia como algo individual?, ¿es la sección policiaca la que captura la atención de los receptores?, ¿tiene algún impacto en ellos?.

En la construcción de la nota roja de este periódico lagunero visualizamos algunos de los aspectos que han detectado algunos investigadores. La contribución de este estudio, está por lo tanto en sus referencias empíricas.

Uno de ellos es la atribución individual al delito, es decir, por lo general los reporteros mencionan el nombre y/o apodo del trangresor, aunque legalmente está penado que estos datos aparezcan ya que son personas "presuntamente culpables" que no han sido procesadas legalmente. Otras variables asociadas a la anterior fueron tomadas en cuenta como la edad, sexo, colonia donde vive y la actividad a la que se dedica el agresor o agresores, víctimas de algún accidente o de los mismos delitos así como los suicidas. Esta última variable permitiría observar si hay una referencia a la situación económica de los sujetos: si ejercen un trabajo remunerado o bien son subempleados o desempleados, relativo a una explicación más social del fenómeno de la violencia.

También se consideró importante analizar los adjetivos utilizados en la redacción, para el agresor o agresores en cuanto a la construcción de ese otro que ejerce la violencia. En el transcurso de la lectura de este diario se constató que la mayoría de ellos eran peyorativos.

Asimismo se tomaron en cuenta algunas variables del estudio La personalización del delito en el discurso noticioso en México (González Molina 1986) como la relación entre el lugar geográfico de los delincuentes y la producción de noticias. 


\section{Metodologia}

\section{Análisis de contenido}

Para realizar el análisis de contenido, se tomó una muestra de 15 periódicos de La Opinión de la Tarde del 27 de septiembre al 13 de octubre de 1995. Se consideró que era un número suficiente de diarios según los parámetros que se han establecido para la muestra en este tipo de trabajos ( $C f r$. Lozano 1994). Este vespertino no se publica los domingos.

Para el análisis se elaboró una definición operacional de la nota roja. Pudo definirse como toda noticia en la sección policiaca de La Opinión de la Tarde donde una o más personas resultaran afectadas. La idea de esta definición fue incluir noticias de accidentes y de suicidios además de las propiamente policiacas como homicidios, robo, riñas etcétera, que también aparecen con frecuencia en el vespertino, muchas de ellas acompañadas con fotografías.

El total de notas examinadas en esos 15 días fue de 385 y la unidad de análisis fue el artículo periodístico que cubría los requisitos de la definición operacional.

Las categorías se construyeron, se discutieron y finalmente se analizaron tres periódicos no incluidos en la muestra para probar si éstas estaban bien definidas. Siete grupos de aproximadamente tres personas en cada uno de ellos se dieron a la tarea de revisar y verificar las categorías. Se discutieron aquéllas en donde habia problemas y se procedió al análisis.

Las categorias construídas para la nota roja fueron las siguientes:

1. Nombre y/o apodo del agresor o agresores, víctimas o suicidas.

2. Nombre de personas cercanas a él o ellos.

3. Edad del agresor o agresores, víctimas o suicidas.

4. Sexo del agresor o agresores, víctimas o suicidas.

5. Actividad a la que se dedica(n).

6. Colonia donde vive(n).

7. Tipo de delito (en caso de agresiones).

8. Lugar donde se cometió el delito, accidente o suicidio.

9. Población o ciudad donde se cometió el delito, accidente, suicidio.

10. Causa del delito, accidente, suicidio.

11. Instrumento de agresión.

12. Utilización de enervantes. 
13. Adjetivos utilizados para el agresor o suicida.

14. A partir del encabezado, ¿parece culpable el agresor?

15. Se conoce o conocía a la víctima.

16. Impresión (color o blanco y negro) de la fotografía

17. La foto aparece con sangre/sin sangre.

\section{Análisis de los receptores.}

Se realizaron 85 entrevistas a personas que conocían La Opinión de la Tarde, inclusive algunas se encontraban hojeando este periódico. Este número no obedece a una muestra probabilística sino se entrevistó a los que se consideró como informantes clave: niños que venden y leen el periódico, personas que se encontraban trabajando en talleres; empleados, amas de casa, estudiantes, así como aquéllos que en esos momentos se encontraban leyéndolo o comprándolo. Cabe señalar que este diario se vende por las mañanas en las principales calles de las ciudades de Torreón, Coahuila; Gómez Palacio y Lerdo, Durango y en las tardes se puede adquirir en los supermercados de cadena.

Las preguntas del cuestionario giraban en torno a identificar, si lo que se había detectado en el análisis de contenido tenía puntos en común con la concepción de los lectores sobre la violencia.

También se realizaron entrevistas a psicoanalistas, abogados, criminólogos así como a los directivos y reporteros de La Opinión de la Tarde.

\section{Resultados}

El periódico construye la nota roja a partir del individuo o individuos que son portadores de la tragedia. Es así como se tiende a personalizar la noticia: en más de la mitad de los casos se menciona el nombre del sujeto o sujetos. Esto puede traer graves consecuencias laborales para los implicados en casos de agresión y que no han sido encontrados culpables, o bien situaciones de pesar para los parientes de víctimas de accidentes o suicidios. (Cuadro 1). 


\section{Cuadro 1}

Aparece nombre del sujeto en la noticia

\begin{tabular}{|l|c|c|}
\hline & Frecuencia absoluta & Frecuencia relativa \\
\hline Sí & 235 & $61.0 \%$ \\
\hline No & 92 & $24.0 \%$ \\
\hline Sólo apodo & 4 & $1.0 \%$ \\
\hline Sujeto colectivo & 35 & $9.0 \%$ \\
\hline Apodo y nombre & 19 & $5.0 \%$ \\
\hline Total & 385 & $100.0 \%$ \\
\hline
\end{tabular}

En poco más de la tercera parte de las notas policiacas también se incluyen los nombres de personas cercanas a éste o éstos, quizá para una mayor identificación por parte de los lectores con la noticia (Cuadro 2).

Cuadro 2

Aparecen nombres cercanos al agresor yło víctima

\begin{tabular}{|l|c|c|}
\hline & Frecuencia absoluta & Frecuencia relativa \\
\hline Sí & 112 & $29.0 \%$ \\
\hline No & 227 & $59.0 \%$ \\
\hline Apodo y nombre & 42 & $11.0 \%$ \\
\hline Sólo apodo & 4 & $1.0 \%$ \\
\hline Total & 385 & $100.0 \%$ \\
\hline
\end{tabular}

Asimismo los reporteros constataron la edad de los actores de las noticias rojas en el $43 \%$ de ellas (Cuadro 3). La característica individual en donde existe más información es en la categoría sexo ya que se consideró en 331 casos (86\%), correspondiendo 304 a hombres (79\%) y sólo-27 a mujeres (7\%). En 54 notas (14\%) no se encuentra especificado este dato ya que se califica con adjetivos como "el sujeto" o "el individuo". 
Necrofilia visual: Análisis de contenido y receptores ...

\section{Cuadro 3}

Edad del sujeto

\begin{tabular}{|l|c|c|c|}
\hline Edades & $\begin{array}{c}\text { Frecuencia } \\
\text { absoluta }\end{array}$ & $\begin{array}{c}\text { Frecuencia } \\
\text { relativa }\end{array}$ & $\begin{array}{c}\text { Frecuencia } \\
\text { acumulada }\end{array}$ \\
\hline Entre 15 y 20 & 58 & $15 \%$ & $15 \%$ \\
\hline Entre 21 y 25 & 54 & $14 \%$ & $29 \%$ \\
\hline Entre 26 y 30 & 12 & $3 \%$ & $32 \%$ \\
\hline Entre 31 y 35 & 12 & $3 \%$ & $35 \%$ \\
\hline Entre 36 y 40 & 19 & $5 \%$ & $40 \%$ \\
\hline Entre 41 y 45 & 4 & $1 \%$ & $41 \%$ \\
\hline De 46 en adelante & 7 & $2 \%$ & $43 \%$ \\
\hline No aparece & 219 & $57 \%$ & \\
\hline Total & 385 & $100 \%$ & $100 \%$ \\
\hline
\end{tabular}

Una variable muy importante en la construcción de ese otro delincuente, desviado de las normas, es su procedencia en el entorno, es decir. la colonia donde vive. La ciudad y sus habitantes también son estereotipados por la prensa. La violencia parece suceder sólo en ciertos ámbitos. Además, es un factor muy importante para el periódico ya que depende del lugar donde ocurre la tragedia para que los habitantes de éste busquen la información en La Opinión de la Tarde. En el $90 \%$ de las notas se encontró su ubicación. El 10\% corresponde a algunos ejidos de la Comarca Lagunera y el $80 \%$ concierne a colonias exclusivamente suburbanas de las ciudades de Torreón y Gómez Palacio. No hay una sola que afecte a colonias clasemedieras. En este sentido, como ya se ha indicado en otros estudios, la violencia parecería situarse, casi en forma exclusiva, en los sectores menos favorecidos económicamente.

Los redactores de la noticia manifiestan su interpretación de la violencia al ámbito de lo individual, cuando subrayan al sujeto con adjetivos calificativos en más de la mitad de las notas (321), que constituyen el $60 \%$ del total. Los peyorativos más utilizados son: vándalo, atracador, malandrin, cholo, rata, ebrio, amante de lo ajeno, mujer de la vida galante, entre otros. En el $40 \%$ de los textos (154) no aparecen estos adjetivos.

Una categoría individual que podría expresar con mayor énfasis una causalidad social o una explicación al fenómeno de la violencia desde una perspectiva histórica, económica, política es la actividad del sujeto o los sujetos, es decir, si éste o éstos ejercen una actividad 
económica remunerada, son subempleados o desempleados. La crisis tiene un origen social, depende de políticas económicas que se aplican en el país, no de los individuos en particular. Es interesante que a los reporteros no les interesa esta explicación. Wolf (1991:219) plantea que esta es una distorsión involuntaria que comenten los reporteros por falta de espacio o tiempo para profundizar sobre los hechos. Así, "El centro de la atención está puesto sobre lo que ocurre, no sobre el por qué ocurre o sobre sus causas profundas". En este impreso, prácticamente en casi todas las notas (96\%) no aparece el "modus vivendi" de los actores. El restante $4 \%$ se divide en personas que ejercían labores como chofer, vendedor, albañil, camionero, velador, payaso. Si bien es difícil afirmar en forma contundente que el desempleo trae como consecuencia la violencia, sí sabemos que son fenómenos que se encuentran en relación y por eso llama la atención que no forme parte del imaginario social de la violencia expresada en el periódico.

Otra serie de categorías se refieren a la construcción de lo que puede denominarse "el relato". La nota roja, a diferencia de otras en donde se supone priva la "objetividad", se construye a manera de historia con sus personajes y su trama. Todos los detalles interesan. Asi las categorías tipo de delito, lugar del delito o de la tragedia, ciudad en que ocurrió el suceso, la causa, el instrumento de agresión o accidente, la utilización de enervantes, los encabezados (que atraen si el agresor parece que ya fue detenido y declarado culpable) y si conoce o conocía a la victima (en el caso de delitos) contribuyen a darle forma a la historia.

En cuanto al tipo de delito o tragedia, los mayores porcentajes los alcanza el robo, que en este caso se especificó que sólo serían tomadas en cuenta las notas donde no hubo agresión a personas sino más bien a comercios o casas-habitación; le siguen los problemas de agresión/lesión: riñas, "picados", etcétera; los asaltos, donde se estableció que en ellos se recogerian los casos donde se violenta a las personas y los accidentes. Es notable que de los porcentajes más bajos en el tipo de delitos se encuentran el homicidio y el suicidio (Cuadro 4). Sin embargo, no es casual que los lectores muestren una gran inseguridad hacia la violencia física porque estas son las notas que La Opinión de la Tarde acentúa en primera plana, aunque su incidencia no sea tal alta como otros delitos.

El lugar donde ocurre el mayor número de delitos o tragedias es en la calle, por consiguiente, gran parte de los lectores (ver infra) piensa que a ellos les puede ocurrir algo similar ya que sucede en condiciones que -según esta visión fatalista-no se pueden controlar. Otros lugares son: los comercios, casas-habitación, antros de vicio y con un mínimo porcentaje, los espacios donde se labora. (Cuadro 5). 
Necrofilia visual: Análisis de contenido y receptores ...

\section{Cuadro 4}

Tipo de delito, accidente o suceso

\begin{tabular}{|c|c|c|c|c|}
\hline \multicolumn{2}{|l|}{$\because n$} & \multicolumn{2}{|c|}{ Frecuencia absoluta } & Frecuencia relativa \\
\hline Homicidio & 4 & 15 & & $4.0 \%$ \\
\hline Lesiónlagresión & & 69 & & $18.0 \%$ \\
\hline Asaltos & & .62 & & $16.0 \%$ \\
\hline Robo & & 69 & & $18.0 \%$ \\
\hline Violación & & 3 & & $.7 \%$ \\
\hline Suicidio & & 1 & & $.3 \%$ \\
\hline Accidente & thes & Alach & दिकी & $10.0 \%$ \\
\hline No hay información & All & $815=8$ & In: & $\because 4$. \\
\hline Otroslvarios & जn: : & $\begin{array}{ll}213, & 119\end{array}$ & कb : & $\therefore \quad 31.0 \%$ \\
\hline & & 385 & & $100.0 \%$ \\
\hline
\end{tabular}

\section{Cuadro 5}

Lugar del delito, accidente o suceso

\begin{tabular}{|l|c|c|}
\hline & Frecuencia absoluta & Frecuencia relativa \\
\hline En la calle & 162 & $42.0 \%$ \\
\hline En comercios & 62 & $16.0 \%$ \\
\hline Casas-habitación & 42 & $11.0 \%$ \\
\hline Antros de vicio & 15 & $4.0 \%$ \\
\hline Lugar donde trabaja & 4 & $1.0 \%$ \\
\hline Otros & 27 & $7.0 \%$ \\
\hline No aparece en la nota & 73 & $19.0 \%$ \\
\hline
\end{tabular}

Existe una íntima relación entre el espacio geográfico de donde proceden las noticias de delitos, accidentes o sucesos y su lugar de producción, correspondiendo a Torreón el mayor porcentaje, seguido de la vecina ciudad de Gómez Palacio, Durango. (Cuadro 6). La infraestructura con que cuentan las empresas periodísticas incide en la menor o mayor posibilidad de cobertura de los hechos. Aunque en la elaboración de este periódico intervienen alrededor de 50 personas en los departamentos de redacción, fotocomposición, formación, fotomecánica y prensa, es indispensable estar cerca del lugar de este tipo de hechos para poder cubrirlos. Mediante información no oficial, se conoció que $L a$ 
Opinión de la Tarde cuenta con un radio de onda corta a través del cual se captan las llamadas de La Cruz Roja, el departamento de bomberos, de policía y acuden inmediatamente al sitio, inclusive antes que los organismos mencionados.

Cuadro 6

Procedencia geográfica

\begin{tabular}{|l|c|c|}
\hline & Frecuencia absoluta & Frecuencia relativa \\
\hline Torreón & 135 & $35.0 \%$ \\
\hline Gómez Palacio, Dgo. & 54 & $14.0 \%$ \\
\hline Durango, Dgo. & 42 & $11.0 \%$ \\
\hline San Pedro, Coah. & 39 & $10.0 \%$ \\
\hline Francisco I. Madero, Coah & 15 & $4.0 \%$ \\
\hline Lerdo, Durango & 12 & $3.0 \%$ \\
\hline Ejidos de Coahuila y Durango & 19 & $5.0 \%$ \\
\hline Otros & 15 & $4.0 \%$ \\
\hline No aparece en la nota & 54 & $14.0 \%$ \\
\hline
\end{tabular}

La causa del delito o accidente puede ser el punto de partida del relato. Abundan los casos en donde el problema económico es fundamental (a pesar de que la actividad del sujeto no se destacó); los accidentes y en gran número sus fotografías, son parte integrante del vespertino. Los sucesos que tienen como motivo las drogas son menores así como las represalias, y prácticamente no hubo un acontecimiento que se desencadenara por el móvil del desamor (Cuadro 7).

Los detalles más específicos de cómo ocurre el accidente o agresión estarían dados por los instrumentos implicados así como el posible uso de enervantes y el conocimiento o no de la víctima. En el $\mathbf{7 7 \%}$ de las notas sí se dio importancia a los instrumentos. Inclusive muchos de esos objetos son motivo de fotografía como las pistolas, armas blancas o los vehículos en el caso de accidentes. (Cuadro 7). 


\section{Cuadro 7}

Causas del delito, accidente o suceso

\begin{tabular}{|l|c|c|}
\hline & Frecuencia absoluta & Frecuencia relativa \\
\hline Económica & 150 & $39.0 \%$ \\
\hline Accidente $\mathrm{n}$ & 42 & $11.0 \%$ \\
\hline Drogas & 23 & $6.0 \%$ \\
\hline Represalias & 19 & $5.0 \%$ \\
\hline Trastomo & 12 & $3.0 \%$ \\
\hline Amoroso & 4 & $1.0 \%$ \\
\hline Otros & 23 & $6.0 \%$ \\
\hline No aparece en la nota & 112 & $29.0 \%$ \\
\hline Total & 385 & $100.0 \%$ \\
\hline
\end{tabular}

En cuanto a los enervantes, destaca el alcohol en relación a los delitos en 42 notas (11\%), con menor proporción la marihuana en 19 casos (5\%) y sólo en 4 ocasiones se utilizaron sustancias tóxicas (1\%). En 320 de los textos analizados (82\%), no apareció la utilización de estas drogas.

El conocimiento o no de la víctima es de suma importancia en la sección policiaca de La Opinión de la Tarde no tanto por la cantidad, sino por la manera en que se cuenta la historia. Los casos en donde el agresor o agresores conocían a su víctima suman 70 (18\%), mientras que en donde explícitamente se hace referencia al desconocimiento es en 19 notas (5\%). En las restantes 296 unidades de análisis no apareció este elemento señalado (77\%). Sin embargo, cabe destacar la importancia de relacionar esta variable con el lugar en donde ocurren los delitos, ya que aparentemente muchos de ellos suceden en la calle sin que las personas se conozcan, pero otros tantos, como se ha comprobado en diversos estudios en el caso de las violaciones, suceden entre parientes, amigos, vecinos. La violencia penetra también los ámbitos domésticos. Es justamente en este sentido que Bisbal (1995:38) entiende la "espiral de violencia" como una forma cultural de entendernos y de vivir en el mundo. Y añadiríamos que no sólo en el exterior, sino en el mismo mundo de la vida privada.

Un gran número de lectores de este periódico (ver infra) señaló que los encabezados de La Opinión de la Tarde fueron importantes para llamar su atención y comprarlo por primera vez. En los encabezados de 189 noticias analizadas (49\%) parecía que los sujetos 
habían sido declarados culpables, o en el caso de los accidentados, que se encontraban en un estado de extrema gravedad, mientras que en el texto se señalaba lo contrario. En 154 del total de las notas $(40 \%)$ no se manifestó de esta manera.

La fotografía es indispensable en la nota roja: es lo que muestra la evidencia de que los sucesos ocurrieron; permite, junto con el nombre y el apodo, la total identificación de los transgresores de la ley. El color en la impresión, facilita la visualización de la sangre, los golpes, las heridas. En la sección policiaca de La Opinión de la Tarde 154 fotografias (40\%) se imprimieron en color y las restantes $231(69 \%)$ en blanco y negro. Puede señalarse el número de fotografías en color como considerable, debido a los costos que se requieren para las mismas, pero es el gancho seguro para los receptores. Sin embargo, pocas son las imágenes que se presentan así (27) que constituyen un 7\% del total. El número de aquéllas que aparecen con golpes y contusiones es de 4 (1\%). La mayoría de las impresiones (327) que representan el $85 \%$ se presentan sin sangre y sin golpes y contusiones. En realidad, muchas de ellas son de los delincuentes o presuntos delincuentes y gran parte de los lectores compran este diario para ver quién sale. Así, es posible coincidir con Gripsrud cuando señala que el estilo y contenido de la prensa popular se puede describir como sensacionalista y personalizado. Si el material per se, no es escandoloso o personal, la prensa popular tenderá a presentarla así, incluyendo además fotos y encabezados dramáticos (Gripsrud 1992: 85-86)

Para contrastar el análisis de contenido de la nota roja en La Opinión de la Tarde se investigó la concepción de los lectores sobre el mismo periódico y la violencia.

Se les preguntó a los receptores en primer término acerca de la frecuencia con que leían el periódico. Aquí se hizo el énfasis sólo en la lectura pues en entrevistas piloto se detectó que en ocasiones lo compraban entre varias personas y todas ellas se constituían en receptores (por ejemplo en los talleres); o bien los encargados de supermercados donde lo venden, lo hojeaban y después lo acomodaban en su lugar para la venta. Del total de personas entrevistadas, 29 lo hacian diariamente, 33 unas tres o cuatro veces a la semana y 23 sólo esporádicamente. Es importante señalar que este periódico sólo se puede adquirir en la calle, puestos de periódico o supermercados ya que no hay distribución domiciliaria. Así tenemos que un número considerable de personas (66), es decir, un $78 \%$ de los entrevistados lo lee por lo menos unas tres veces a la semana.

Se les cuestionó también sobre aquéllas secciones que les gustaban más del periódico. Interesaba averiguar si la sección policiaca tenía preferencia. Un poco más de la mitad de los lectores (49 personas) comentaron que leían este periódico por la nota roja. Un hombre de 72 años, jubilado de la SARH respondió: 
Todas, pero las noticias policiacas hay veces que hasta las leo dos veces (sic).

También se inquirió por qué se habian interesado en La Opinión de la Tarde, preguntando acerca de los motivos para comprarlo o leerlo por primera vez. Aquí se encontró que lo impactante del periódico: fotografias, encabezados, noticias trágicas y la portada habían sido ganchos efectivos para atraer al ahora receptor cautivo. Del total de informantes 10 ubicaron las fotografías como el atractivo del diario. Un joven de 24 años de oficio mecánico dijo:

Pues me lo prestaron ahi en el trabajo. En el taller un compañero lo compraba y yo lo veía. Me llamaban la atención las fotografias y luego, poco a poco me fui interesando por la información (sic).

Veinte entrevistados se interesaron explícitamente por la nota roja. Un licenciado en derecho de 31 años que trabaja en un taller de carpintería dijo:

La verdad por la sección roja, por los accidentes, todo eso (sic).

El encabezado también fue motivo para seis personas de acercarse por primera vez a este impreso. Un hombre que se dedica a lavar carros de 56 años señaló que la primera vez que lo compró fue porque vio un encabezado que decía: SE suIcidó. Otros cinco informantes indicaron que se habian interesado por la portada y cinco más señalaron que su motivo había sido la curiosidad. Las respuestas de los demás entrevistados varian: unos señalan que por recomendación, otros por averiguar quién salía conocido Unos más por razones de trabajo, como un señor de 52 años de oficio bolero que dijo:

Es que los clientes me pedían algo para leer mientras los boleaba y me pedian ese periódico.

Para completar la pregunta anterior se indagó: ¿Qué es lo que le llama más la atención ahora de este periódico?

Cabe destacar aquí, que a pesar de que algunas personas de otros sectores sociales desprecian este diario, 28 de los receptores lo señalaron como informativo. Nuestro interrogado, mecánico de 24 años comentó: 
Primero las noticias, porque hay que estar bien informado, y como yo estoy casi todo el día en el taller, no puedo verlas en la televisión.

Para otros 16 entrevistados, las fotografías son lo más importante que este diario ofrece, ya que según éstos son oportunas, rápidas y realistas. A varios les entusiasma comprarlo por la sección de espectáculos y la página deportiva.

También se consideró importante conocer si los lectores de La Opinión de la Tarde, leían o compraban otro periódico para informarse, ya que según los directivos este impreso está enfocado a lo que ellos llaman un mercado-meta, distinto al que compra el matutino. Lo anterior se confirma ya que un poco más de la mitad (46 personas), sólo compran el vespertino. El resto compra El Siglo de Torreón o La Opinión los fines de semana, cuando buscan empleo (por los avisos de ocasión, abundantes en El Siglo). Tres informantes señalaron que leen los matutinos atrasados cuando se los prestan. Ciertamente se puede observar que consideran completo el periódico de su preferencia como lo indica un hombre de 29 años, de oficio albañil:

No compro ningún otro, pues ahí sale todo lo que uno debe saber (sic).

Aubague señala que la nota roja debía abrir espacios de solidaridad al compartir la tragedia humana pero, al construirse para el consumo, el receptor toma distancia y la ve como un espectáculo. En ese sentido se elaboraron dos preguntas: ¿Conoce a alguien que haya salido en la nota roja de este periódico? y ¿Qué pensaría si un accidente o la muerte de una persona cercana a usted apareciera en La Opinión de la Tarde?

En cuanto a la primera pregunta, más de la mitad de los interrogados, 47 personas, indicaron que había salido alguien conocido de ellos en esa sección. Pero lo interesante son sus respuestas, que más que solidaridad, expresan curiosidad por la vida privada y situación de otros. Un señor de oficio taxista, de 37 años comentó:

Sí, muchos "compas" que son ratas y los agarran, y pues son conocidos de la colonia o donde trabajo (sic).

Un hombre de 35 años que se dedica a la albañilería dijo;

¡Ah ¡ cómo no. La otra vez salió un conocido que había golpeado a su mujer (sic). 
Necrofilia visual: Análisis de contenido y receptores ...

En relación a la segunda pregunta, casi la mitad de los entrevistados (37) señalaron que no les gustaría que aparecieran familiares y amigos en La Opinión de la Tarde. Tal parece que la solidaridad se restringe cada vez más y solamente al ámbito familiar. Un hombre de 32 años que trabaja de guardia señaló:

No, pues... se siente mal porque ver la foto se siente gacho, pero para una persona que no es nada pues no le importa, pero un familiar se siente feo (sic).

Sin embargo, a otros 15 no les importaría que sus familiares tomaran parte en este diario. Pocos son los que se enojarían con los reporteros de La Opinión de la Tarde (6), a otros les daría pena (9) o sentirian que se burlan de ellos (2). Un poco más de la sexta parte (15) les parece importante que la prensa recoja todo tipo de noticias, incluyendo las de sus familiares y muestran resignación ante lo que parece inevitable: salir en el periódico. Un señor de 37 años que se dedica a la reparación de electrodomésticos dijo:

Nada, cómo que qué. Si sale es porque necesitaba salir, que era un caso importante o algo. Toda la gente que sale en el periódico tiene familia y no dicen nada, ni modo. Tienen que salir (sic).

Para ubicar si los lectores de este vespertino coincidían con la posición fatalista que se presenta en la construcción de la noticia, se les preguntó si ellos pensaban que lo que acontecía en la nota roja les podía suceder a ellos. La abrumadora mayoría (70) contestaron afirmativamente y muchos recurrían a Dios para explicar que pasaba finalmente, lo que él quería. Otros señalaron, que al salir a la calle, estaban expuestos a todo. Un joven de 26 años que se dedica a la mensajería dijo:

Pues creo que sí, siempre te pueden hacer algo. Y a fin de cuentas pasa lo que Dios quiere. Además el rumbo del centro y por mi casa es peligroso. Ya te pueden asaltar en cualquier lugar en la noche. Que me maten a lo mejor no, pero otra cosa sí (sic)

Y un señor de 50 años cuyo oficio es la venta de tacos comentó:

Yo creo que sí, porque pues todo pasa en la calle y por lo menos, para ir al trabajo, uno anda en la calle (sic). 
En este sentido, sí puede afirmarse que lo que se maneja en los textos tiene una incidencia y/o coincidencia con la cosmovisión de los lectores, sugiriéndola o reafirmándola, pero ésta definitivamente es pasiva, tiende a conminar a los individuos y a desplazarlos hacia la vida privada, donde es posible sentirse seguro.

Algunas personas, durante las entrevistas piloto, explicaron que no les gustaban las fotografías pero les atraía mirarlas y se quiso averiguar si éstas tenían un impacto en los receptores. Casi la cuarta parte (24) ubica las imágenes como sensacionalistas y expresan que es una estrategia de venta del diario, sin embargo explican que son importantes, por ejemplo, las de los delincuentes, para saber quiénes son y cuidarse de ellos. Hay mucha aceptación de una parte de la sección policiaca que aparece semanalmente y se llama Galería de malandros, en donde se exponen las fotografias de los presuntos delincuentes de la semana. A otro gran número de personas (28) les disgustan, a otras (3) les producen asco y a unos más (2) ofensivas. Sin embargo, 15 personas más comentan que éstas son muy realistas, y que deben mostrarse porque así es el mundo.

Uno de los grandes analistas de la cultura mexicana concluye que: "En la nota roja, entre mentiras y drásticas inexactitudes (nada es como se cuenta, salvo los muertos), el morbo adquiere cualidades de 'pesadilla tranquilizadora'. Y el gusto por lo sanguinoliento -entreveramiento de horror inducido y placer controlado- se vierte en relatos pavorosos donde la Decencia Ultrajada (el reportero que se espanta a nombre de la sociedad, las conversaciones sobre el crimen de moda que hacen las veces de parábolas bíblicas) combina espantos reales y maledicencias gozosas" (Monsiváis 1994:11).

\section{Conclusiones}

Es posible decir con Gripsrud (1992:84) que la prensa popular varía de un lugar a otro. Así, mientras en otros países los periódicos "amarillistas" enfatizan más los accidentes o la vida privada de personajes públicos, los resultados del análisis de contenido de $L a$ Opinión de la Tarde destacan la construcción de la nota roja centrada en el delincuente, en el individuo transgresor -que como diría Durkheim! - no está bien socializado. El

1 Durkheim, en su famoso estudio El Suicidio considera que el hombre moderno se mata debido a la pérdida de integración de la sociedad y a la marcada debilidad de normas sociales que le indiquen su proceder. De hecho, a mayor cohesión social, menor tasa de suicidios y parafraseándolo diríamos de violencia. 
hecho histórico de la violencia se elimina, quedando el fenómeno en un vacío, sólo sostenido por los portadores de las tragedias, que deben ser sometidos -mediante la leyal cauce de las normas que no son cuestionadas.

$\mathrm{El}$ examen de los textos noticiosos de la sección policiaca de este impreso, indican que la discusión sobre la ética y los medios debe ser puesta en un primer término. La legislación, por ejemplo, sobre la prensa no tiene ninguna incidencia en quienes se dedican al negocio de la información. El jefe de información de La Opinión de la Tarde señaló que jamás habían tenido problemas con la Secretaría de Gobernación y que la regulación era un mito.

La violencia, en este vespertino, parece hermana gemela de la pobreza. Ello pudiera tener implicaciones para los individuos particulares, como ya se ha indicado, pero también puede legitimar otras violencias en contra de los habitantes de los barrios y colonias suburbanas. El imaginario social presente en la nota roja pareciera decir que esta porción de la población (que es la mayoría) ocasiona los conflictos porque no controlan sus instintos, sus bajas pasiones. Y ellos mismos, coincidiendo con Aubague (1987), se sienten sujetos al control de fuerzas que no pueden impedir, que son inevitables.

Los análisis tanto de Gripsrud (1992) como de Langer (1992) poniendo énfasis en la interpelación de los lectores de esta prensa amarilla a través de los relatos, fueron de mucha utilidad, ya los textos analizados estaban armados a modo de historia y esto parece ser, junto con las fotografias, uno de los mayores atractivos del vespertino. Esta idea, pudiera sugerir futuras investigaciones en dos vías. Por un lado, los receptores de este diario se muestran interesados en la información pero no alejada de la vida cotidiana como es el estilo periodístico de las noticias económicas o políticas. Quizá es la construcción de este tipo de noticia, que los aleja de las mismas. Por otro, quizá podrían elaborarse análisis de contenido regionales para observar cuál es la cobertura de los periódicos de estas zonas periféricas, pues aparentemente sólo se informa de ellas, en la nota roja.

Aunque en este estudio no se tomó en cuenta la mediación del sexo para la lectura de este periódico y sólo el $20 \%$ de los entrevistados fueron mujeres, sí se puede observar que ellas tienen poca preferencia por la nota roja, acercándose más a secciones como $\mathrm{La}$ Tía Soraya mediante la cual se busca pareja. Quizá otras investigaciones, centradas en el género, pudieran profundizar en este aspecto.

Los estudios de Uribe (1995), Bisbal (1995) y Aubague (1987) son muy pertinentes para la realidad latinoamericana, ya que a través de ellos se pone en la mesa la cuestión de que la violencia es una matriz cultural que no sólo tiene expresión en los medios, sino 
en la vida colectiva misma. Los receptores de La Opinión de la Tarde muestran recelo ante sus vecinos y poca solidaridad en el ámbito conceptual, inclusive con sus familiares, pero esto es una expresión simbólica de cómo nos construimos (o destruimos) como país.

\section{Bibliografía}

AUBAGUE, Laurent (1987). "Alarma y las imágenes de la muerte: de lo imaginario cultural a la función ideológica", en Estudios sobre las culturas contemporáneas, Vol. 1, núm. 2.

BISBAL, Marcelino (1995) "Violencia, inseguridad ciudadana y medios $\multimap$ intentando comprender la perspectiva massmediática de la violencia", en Jorge Iván Bonilla Vélez (compilador). Violencia, medios y comunicación, México, Trillas.

Cervantes BARBA, Cecilia (1994). "Análisis de contenido y etnografia en el estudio de la producción de noticias", en Cervantes Barba, Cecilia y Sánchez Ruiz, Enrique (coordinadores). Investigar la Comunicación. Propuestas iberoamericanas, México, Universidad de Guadalajara, CEIC, ALAIC.

Cervantes Barba, Cecilia (1996). "Valores noticiosos en el periodismo televisivo de nota roja", en Comunicación y Sociedad, núms. 25 y 26, septiembre 1995 y abril 1996, México, Universidad de Guadalajara.

De Fleur, M. L y Ball-RoKeach, S. (1982). Teorias de la Comunicación de masas, México, Paidós.

DuRKHEIM, Emile (1974). El Suicidio, Serie Nuestros Clásicos, núm. 39, México, UNAM. GoldsMith, John y CRINKEL, Julie (1993). "Mortalidad de los jóvenes adultos: comparaciones internacioinales", en Salud Pública de México, Vol. 35, núm 2. México.

GoNZÁLEZ MolinA, Gabriel (1986). "Legitimidad cultural: la personalización del delito en el discurso noticioso de México". II Congreso Nacional de Criminología. Colima. GonZÁlez Molina, Gabriel. "Valores noticiosos. La distribución desigual del acceso periodístico". Avances de Investigación, núm. 3, Colima, Universidad de Colima. GRIPSRUD, Jostein (1992). "The aesthetics and politics of melodrama", en Peter Dahlgren and Colin Sparks (eds). Journalism and popular culture, Newsbury Park, California, Sage.

HERNER, Irene (1979). Mitos y monitos. Historietas y fotonovelas en México, México, Nueva Imagen. 
Necrofilia visual: Análisis de contenido y receptores ...

KIM, Joohoan (1995). "Killing and dying in the newspapers". A content analysis on New York Times and New York Newsday. Http://www.cis.penn-edu/sjokim/killin.txt LANGER, John (1992). "Truly awful news on television", en Peter Dahlgren and Colin Sparks (eds). Journalism and Popular culture, Newsbury Park, California, Sage.

LOZANO RENDÓN, José Carlos (1994). "Hacia la reconsideración del análisis de contenido en la investigación de los mensajes comunicacionales", en Cervantes Barba, Cecilia y Sánchez Ruiz, Enrique (coordinadores). Investigar la Comunicación. Propuestas iberoamericanas, México, Universidad de Guadalajara, CEIC, ALAIC.

LozANo RENDón, José Carlos (1996). Teoria e investigación de la comunicación de masas, México, Alhambra Mexicana.

Monsıváis, Carlos (1994). Los mil y un velorios, México, Alianza Cien.

URIBE, María Teresa (1995). "Violencia: algo más que disparos, víctimas y sangre", en Medios de comunicación y responsabilidad ciudadana d, II Encuentro Nacional de la Sociedad Civil. Conferencia Episcopal Venezolana. Caracas, Universidad Católica Andrés Bello.

Wolf, Mauro (1991). La investigación de la comunicación de masas. Crítica y perspectivas, México, Paidós. 